\title{
EFEITOS DA LEGISLAÇÃO AMBIENTAL NA PROTEÇÃO DA ÁREA DE PROTEÇÃ O AMBIENTAL DO GUARIROBA, MATO GROSSO DO SUL
}

\author{
CAMARGO, Carolina Maria Jorge; CAMARGO, Luan José Jorge; \\ OLIVEIRA, Ademir Kleber Morbeck de
}

Universidade Anhanguera-Uniderp. Programa de Pós-Graduação em Meio Ambiente e Desenvolvimento Regional. Rua Alexandre Herculano, 1400 - CEP 79037-280 Campo Grande, MS, Brasil.

E-mail: luancamargo@hotmail.com

\begin{abstract}
Resumo
O presente trabalho discute a aplicação da legislação ambiental em uma Área de Proteção Ambiental (APA), na Bacia do Guariroba, Campo Grande, Mato Grosso do Sul, responsável por 50\% da água utilizada no abastecimento urbano da cidade. Este estudo foi desenvolvido por meio de levantamento bibliográfico relacionado às políticas públicas adotadas na APAe de análises feitas in loco, avaliando a validade e eficácia da aplicação da legislação nesta área de proteção ambiental, através dos pontos de vista jurídico, social e ambiental. Os resultados indicam que a legislação ambiental não está sendo aplicada e que ocorre uma omissão do poder público, que não fiscaliza o cumprimento das normas que deveriam reger esse tipo de unidade de conservação, que sofre com processos de erosão, assoreamentos, além da substituição contínua da vegetação nativa por espécies exóticas, tais como braquiária e eucalipto, o que ameaça a biodiversidade da região e os recursos hídricos da área.
\end{abstract}

Palavras-chave: Desenvolvimento Sustentável; Unidades de Proteção; Área de Proteção Ambiental; Recurso Hídrico; Bacia Hidrográfica.

\begin{abstract}
This paper discusses the application of environmental legislation in an Environmental Protection Area in the Guariroba Basin, Campo Grande, Mato Grosso do Sul, which accounts for 50\% of water used in urban water supply in the city. The methodology of the research included a review of the bibliography related to public policies adopted in the area of Environmental Preservation and local analyses, assessing the validity and the effectiveness of enforcement in this area of environmental protection, considering legal, social and environmental points of view.The results indicate that environmental legislation is not being enforced and that there is a failure of public power, which does not monitor compliance with the standards that should govern this type of conservation unit, which suffers from erosion, silting of water resources, and continuous substitution of native vegetation by exotic species, such as pasture and eucalyptus, which threatens the region's biodiversity and the water resources of the area.
\end{abstract}

KEYwords: Sustainable Development; Protection Units; Area of Environmental Protection; Water Resources; Watershed. 


\section{INTRODUÇÃ̃o}

O Brasil, em relação aos outros países, possui um grande potencial hídrico, totalizando $15 \%$ das reservas de água doce no mundo e $53 \%$ do total existente na América do Sul. Porém, a distribuição desses recursos no território nacional não é igualitária, com somente 3\% na Região Nordeste, $12 \%$ nas Regiões Sul e Sudeste e $70 \%$ para a Região Norte, que possui a menor população (REBOUÇAS et al., 2006; RODRIGUES, 2009).

$\mathrm{Na}$ Região Centro-Oeste se encontra $15 \%$ da reserva superficial de água doce. O Mato Grosso do Sul, no entanto, é considerado a segunda maior potência hídrica do Brasil, pois possui o maior manancial subterrâneo de água doce do mundo, o Aquífero Guarani, que ocupa $70 \%$ do subsolo do Estado (RODRIGUES, 2009), o que torna a Região Centro-Oeste uma das maiores reservas de água doce do país.

Mato Grosso do Sul tem como sua capital a cidade de Campo Grande, localizada predominantemente na Bacia Hidrográfica do Rio Paraná, Sub-bacia do Rio Pardo, com uma pequena parte do município situada a noroeste, compondo a Bacia do Rio Paraguai (CAMPO GRANDE, 1999; RODRIGUES, 2009).

Campo Grande está em pleno crescimento, situação originada por levas de migrantes que chegam para ocupar os espaços de uma capital em expansão. A captação de água para o abastecimento da cidade é feita de duas formas. A primeira, superficial, nos córregos Guariroba e Lajeado. Já a segunda corresponde a 94 poços subterrâneos (CAMPO GRANDE, 1999; RODRIGUES, 2009). Porém, a maior parte dda captação é feita no córrego Guariroba.

Os recursos hídricos subterrâneos estão relacionados as três formações geológicas diferentes existentes em Campo Grande. A primeira e mais superficial se localiza a oeste da cidade e está relacionada aos arenitos do Grupo Bauru; a segunda abrange as rochas da Formação Serra Geral; e a terceira encontra-se em nível profundo, contendo as rochas da formação Botucatu, que abriga o Aquífero Guarani (GUARIROBA, 2009). Esse abundante manancial hídrico que corta o Estado do Mato Grosso do Sul pode proporcionar uma "sadia qualidade de vida" para a população regional e local, pois beneficia direta e indiretamente a qualidade de vida das pessoas, a economia e o equilíbrio ambiental local.

Levando-se em consideração a importância da manutenção da qualidade desses recursos, é fundamental que se aplique meios eficazes de conservação dos mananciais, porque se trata de fonte essencial na conservação da vida em geral, de modo a assegurar cada vez mais o ambiente ecologicamente equilibrado, garantindo uma melhor qualidade de vida a todos os seres vivos. Assim, devem os Estados-Membros, como é o caso de Mato Grosso do Sul, e a União tutelar esse "bem comum de todos", conhecido na ciência jurídica como bem de natureza coletiva.

É justamente nesse sentido que a Constituição da República Federativa do Brasil, de 1988, em capítulo específico sobre "Meio Ambiente", trata de maneira eficaz o ambiente, dispondo em seu artigo 225:

"Art. 225: Todos têm direito ao meio ambiente ecologicamente equilibrado, bem de uso comum do povo e essencial à sadia qualidade de vida, impondose ao Poder Público e à coletividade o dever de defendê-lo e preservá-lo para as presentes e futuras gerações."

Mas não é só nessa perspectiva que há a efetiva tutela ambiental realizada pelo Poder Público e a coletividade. $\mathrm{O}$ conceito se estende também aos espaços territoriais e seus componentes, podendo ocorrer alterações na legislação ambiental, neste caso somente mediante lei.

$\mathrm{O}$ artigo 225 estabelece, em seu parágrafo $1 .^{\circ}$, inciso III, o que é dever do poder público:

\footnotetext{
"em todas as Unidades Federais (entende-se por União, Estado Municípios e Distrito Federal), espaços territoriais e seus componentes a serem especialmente protegidos,
} 
sendo a alteração e a supressão permitidas somente através de lei, vedada qualquer utilização que venha a comprometer a integridade dos atributos que justifiquem sua proteção".

Para a regulamentação desse direito constitucionalmente garantido às presentes e futuras gerações, foi elaborada a Lei Federal n. ${ }^{\circ}$ 9.985, de 18 de julho de 2000, que instituiu o Sistema Nacional de Unidades de Conservação da Natureza (SNUC) e sistematizou o conjunto de unidades de conservação, espalhadas até então em várias legislações esparsas de maneira fragmentada. Por meio dessa Lei Federal foi possível criar novos tipos de áreas de preservação, definindo-as em uma sistemática que se compõe de dois grupos fundamentais, apresentando unidades reunidas de acordo com seus objetivos, de preservação ou conservação ambiental (OLIVEIRA, 2009).

O conceito de Unidade de Conservação encontra-se delimitado no Art. $2 .^{\circ}$, inciso I, da Lei n. ${ }^{\circ} 9.985 / 2000$ :

"Espaço territorial e seus recursos ambientais, incluindo as águas jurisdicionais, com características naturais relevantes, legalmente instituídos pelo Poder Público, com objetivos de conservação e limites definidos, sob regime especial de administração, ao qual se aplicam garantias adequadas de proteção."

Portanto, o objetivo se concentra no nome e na definição, qual seja: a conservação dos atributos ecológicos do espaço territorial devidamente delimitado e seus recursos ambientais (SILVA, 2009).

Com base na Lei n. ${ }^{\circ}$ 9.985/2000, "as unidades de conservação integrantes do SNUC dividem-se em dois grupos:

I - Unidade de Proteção Integral: a) Estação Ecológica; b) Reserva Biológica; c) Parque Nacional; d) Monumento Natural; e) Refúgio de
Vida Silvestre.

II - Unidade de Proteção Sustentável: a) Área de Proteção Ambiental; b) Área de Relevante Interesse Ecológico; c) Floresta Nacional; d) Reserva Extrativista; e) Reserva de Fauna; f) Reserva de Desenvolvimento Sustentável; g) Reserva Particular do Patrimônio Natural.

Nessa perspectiva, os córregos que abastecem a cidade de Campo Grande são protegidos por Áreas de Proteção Ambiental (APAs), regulamentadas em nível Federal pela Lei n. ${ }^{\circ}$ 9.985/ 2000 (SNUC). Segundo o artigo 15 "caput" dessa legislação, Áreas de Proteção Ambiental podem ser definidas como:

"... áreas em geral extensas, com um certo grau de ocupação humana, dotada de atributos abióticos, bióticos, estéticos ou culturais especialmente importantes para a qualidade de vida e o bem-estar das populações humanas, e têm como objetivos básicos proteger a diversidade biológica, disciplinar o processo de ocupação e assegurar a sustentabilidade de uso dos recursos naturais."

Segundo Silva (2010), são espaços também protegidos, mas a intensidade da proteção ambiental é menor do que a que se aplica nas Unidades de Proteção Integral, porque, ao contrário destas, permitem o uso direto dos seus recursos naturais. Seu objetivo básico não é preservar a natureza, mas compatibilizar a conservação desta de maneira sustentável, segundo o Art. $7^{\circ}, \S 2 .^{\circ}$, da Lei n. ${ }^{\circ}$ 9.985/2000.

A APA do Guariroba é considerada uma unidade de conservação de uso sustentável, que poderá ser objeto de ações exploratórias para o desenvolvimento de atividades produtivas de cunho natural, que proporcionem a máxima proteção das características naturais e até mesmo paisagísticas. É importante observar que as áreas de proteção ambiental tanto podem ocorrer em propriedades públicas como em lugares privados; não são áreas de 
conservação e preservação ambiental exclusivas do poder público.

Apesar de atualmente existir no município três APAs - Mananciais do Córrego do Guariroba, Mananciais do Córrego Lajeado e a da Bacia do Córrego Ceroula -, a mais relevante é a Área de Proteção Ambiental do Guariroba, principal fonte de abastecimento de água de Campo Grande. Ela é responsável por $50 \%$ de todo o abastecimento local, sendo criada por decorrência da necessidade que o município apresentava, na época, de recuperar e conservar a principal fonte de água doce no município (GUARIROBA, 2009).

AAPA do Guariroba iniciou-se com a formação da represa (Reservatório do Guariroba), acessada pela BR-262 a aproximadamente $35 \mathrm{~km}$ de Campo Grande. Anteriormente a área era explorada pela Empresa de Saneamento de Mato Grosso do Sul (Sanesul), responsável pela construção do reservatório e implantação do sistema de captação e adução da água da APA para a cidade em 1985; hoje quem realiza essa função é a concessionária Águas Guarirobas S.A. (GUARIROBA, 2009).

Levando em consideração a importância dessas APAs, que abrigam as principais fontes de água potável do município, o objetivo principal deste estudo foi examinar a real situação da sub-bacia hidrográfica do Guariroba.

Visou-se discutir a regulamentação de Áreas de Proteção Ambiental no Brasil, a partir da Constituição Federal de 1988, pretendendo demonstrar se há validade e eficácia na aplicação da legislação ambiental nesta área municipal, e avaliando se os impactos causados ao ambiente estão sendo efetivamente tutelados do ponto de vista jurídico e ambiental.

\section{Metodologia}

Este estudo foi desenvolvido primeiramente por meio de levantamento bibliográfico, relacionado às políticas públicas de manejo adotadas na referida área, e em legislações referentes ao estudo, para enquadrar a previsão legal à realidade atual da sub- bacia. Posteriormente foram feitas visitas técnicas à região, para avaliar a quais impactos antrópicos está sendo submetida. Assim, buscou-se demonstrar e analisar a validade e a eficácia da aplicação da legislação na APA do Guariroba.

\section{RESUltados E DISCUSSÃO}

A APA engloba uma área total de aproximadamente $360 \mathrm{~km}^{2}$, com seu território composto basicamente pela ocupação rural. As propriedades são de natureza rural privada, voltadas à prática da pecuária extensiva, com $82 \%$ do território da APA composto essencialmente de pastagens artificiais de Brachiaria decumbes Stapf (GUARIROBA, 2009).

A maior parte dos proprietários não efetua os devidos manejos estabelecidos pelo programa de proteção da APA, alegando que o custo para a manutenção ecológica é elevado, em relação à renda obtida no exercício de suas atividades econômicas, inviabilizando sua aplicação.

Dessa maneira, a legislação ambiental não é cumprida na maioria das propriedades, seja em relação às Áreas de Preservação Permanente (APP) e/ou de Reserva Legal, que não possuem o tamanho preconizado pela lei.

É importante lembrar que as APPs e Reservas Legais estão discriminadas na Lei n. ${ }^{\circ}$ 4.771/65 (Código Florestal), sendo alguns dispositivos alterados pela Lei Federal n. ${ }^{\circ} 7.803 / 89$. As APPs estão regulamentadas nos artigos $2 .^{\circ}$ e $3 .^{\circ}$ do Código Florestal, e podem ser definidas como áreas que podem ser cobertas ou não por vegetação nativa, com a função de preservar e conservar o ambiente, assim como preservar os recursos hídricos, a paisagem, a estabilidade ecológica, a biodiversidade, o fluxo gênico de fauna e flora, proteger o solo e assegurar a qualidade de vida das populações humanas (REBOUÇAS et al., 2006).

Ressalta-se que qualquer intervenção em área de preservação permanente, seja em APAs ou não, pode gerar uma significativa interferência nas formações ripárias, devendo possuir uma extensão 
específica a ser protegida de acordo com a largura do recurso hídrico, podendo ser ele rio, nascente, represa ou lago.

O Código Florestal atribui a importância de se preservar as APPs para impedir vários tipos de impacto ambiental aos recursos hídricos locais, utilizando-se das formações ripárias na manutenção dos ecossistemas, evitando, por exemplo, escassez da água, erosão e assoreamento, perda da qualidade da água e da biodiversidade, entre outros fatores (COELHO, 2010).

Já a Reserva Legal pode ser definida, com base no Código Florestal, como "área localizada no interior de uma propriedade ou posse rural, excetuada a de preservação permanente, necessária ao uso sustentável dos recursos naturais, à conservação e reabilitação dos processos ecológicos, à conservação da biodiversidade e ao abrigo e proteção de fauna e flora nativas" (REBOUÇAS et al., 2006).

Portanto, é a área de Reserva Legal que sofre uma limitação administrativa, e ela vem discriminada no Art. 16 do Código Florestal, segundo o qual o proprietário ou o possuidor somente poderá utilizála sob manejo florestal sustentado - o que deveria ocorrer na APA e não vem sendo cumprido pelos proprietários privados, devendo se efetivar mediante projeto próprio e com prévia autorização do Poder Público (REBOUÇAS et al., 2006).

A não observância dos proprietários sobre a prática de um manejo adequado na APA tem gerado várias ocorrências de passivos ambientais, associados diretamente à erosão e principalmente à supressão vegetal em APPs.

Jurisprudência do Superior Tribunal de Justiça, publicada no Diário de Justiça do dia 17/12/2009, entende que:

"(...) Inexiste direito adquirido a poluir ou degradar o meio ambiente. O tempo é incapaz de curar ilegalidades ambientais de natureza permanente, pois parte dos sujeitos tutelados as gerações futuras - carece de voz e de representantes que falem ou se omitam em seu nome. Décadas de uso ilícito da propriedade rural não dão salvo-conduto ao proprietário ou posseiro para a continuidade de atos proibidos ou tornam legais práticas vedadas pelo legislador, sobretudo no âmbito de direitos indisponíveis, que a todos aproveita, inclusive às gerações futuras, como é o caso da proteção do meio ambiente. As APPs e a Reserva Legal justificam-se onde há vegetação nativa remanescente, mas com maior razão onde, em consequência de desmatamento ilegal, a flora local já não existe, embora devesse existir. Os deveres associados às APPs e à Reserva Legal têm natureza de obrigação propter rem, isto é, aderem ao título de domínio ou posse. Precedentes do STJ. Descabe falar em culpa ou nexo causal, como fatores determinantes do dever de recuperar a vegetação nativa e averbar a Reserva Legal por parte do proprietário ou possuidor, antigo ou novo, mesmo se o imóvel já estava desmatado quando de sua aquisição. Sendo a hipótese de obrigação propter rem, desarrazoado perquirir quem causou o dano ambiental in casu, se o atual proprietário ou os anteriores, ou a culpabilidade de quem o fez ou deixou de fazer. Precedentes do STJ. Recurso Especial parcialmente conhecido $\mathrm{e}$, nessa parte, não provido. (REsp 948.921/SP, Rel. Ministro HERMAN BENJAMIN, SEGUNDA TURMA, julgado em 23/10/2007, DJe 11/11/ 2009)."

Portanto, a jurisprudência é clara ao demonstrar que devem ser respeitadas as áreas de proteção permanente (APP) como as Reservas Legais, cabendo ao proprietário o dever de recuperá-la, caso haja eventual dano ao ambiente. Porém, apesar de a determinação legal ser bastante evidente em relação a responsabilidade objetiva do proprietário, na APA do Guariroba o manejo e a recuperação são inexistentes, pela falta de 
fiscalização do poder público.

Outro aspecto prejudicial da proteção da APA do Guariroba é a substituição da vegetação natural por pastagens, em decorrência da criação do gado, que avançam significativamente em áreas úmidas, gerando erosão acelerada, causada pelo pisoteamento do gado em áreas de acesso aos cursos d'água.

Além desses impactos ambientais negativos, há também risco de queimada, provocada para que se tenha renovação da pastagem; o grande problema, no entanto, é a falta de uma educação adequada a esses proprietários para que realizem um manejo adequado na APA do Guariroba.

Os proprietários rurais dessa área deveriam utilizar ações que garantam as mudanças no sistema produtivo praticado na APA, e apresentar alternativas técnicas para viabilizar e/ou aumentar a produção agropecuária, prevalecendo a proteção ambiental sustentável. A produção agropecuária proveniente das propriedades privadas pode ser alta, podendo ser aumentada desde que se apliquem tecnologias específicas para o segmento, que contenham uma melhoria do sistema produtivo de maneira equilibrada e sustentável, o que atualmente não ocorre na APA.

O manejo dos animais e a transformação no solo têm causado impactos expressivos na bacia do Guariroba, pois enseja processos erosivos e assoreamento dos corpos de águas naturais, bem como do reservatório (GUARIROBA, 2009).

Outro impacto detectado na área da APA é a plantação de eucalipto, que cresce dia-a-dia, pelo alto retorno econômico, e afeta diretamente a biodiversidade local, o lençol freático e ameaça a perenidade das nascentes.

Portanto, para que a área atinja sua finalidade, é de extrema importância que os proprietários rurais obedeçam às diretrizes estabelecidas nas legislações, a fim de garantir uma real proteção ambiental. Se não forem obedecidas, o ambiente como um todo, incluindo os recursos hídricos, estará prejudicado, podendo essa realidade se tornar uma enorme catástrofe, que poderá provocar a escassez de água na principal reserva hídrica que abastece o município de Campo Grande.

É imprescindível enaltecer que outro aspecto prejudicial na preservação da APA são os próprios caracteres físicos e ambientais do local. O primeiro ponto a ser levantado é a característica arenosa do solo na região. Combinado com estradas rurais que não obedecem aos padrões ambientais, e juntamente com a atuação da chuvas nesta localidade, geram erosões e assoreamento dos córregos.

Outra questão a ser observada são os fragmentos vegetais existentes na área, do tipo secundário, resultado da contínua retirada de madeira na região, levando ao empobrecimento do solo e à perda de biodiversidade, o que é evidente pela presença das espécies de árvores indicativas de áreas que sofreram modificações antrópicas, tais como Xylopia aromatica (Lam.) Mart., Jacaranda caroba (Vell.) A. DC., Diptychandra aurantiaca Tul., Kielmeyera coriacea Mart. \& Zucc., Anadenanthera falcata (Benth.) Speg., Qualea grandiflora Mart., Vochysia tucanorum Mart., entre outras.

É evidente que a falta de observação das legislações ambientais ocasionam a degradação; portanto, é necessário que tanto o poder público quanto os particulares fiscalizem e cumpram a legislação ambiental.

Além disso, a coletividade deve tomar ciência da realidade local, fiscalizando e cobrando medidas a serem tomadas pelo governo, a fim de garantir o cumprimento das diretrizes traçadas na APA para a proteção da bacia do Guariroba. A aplicação da legislação deveria ser uma constante, já que este mecanismo é o que permite a manutenção do ambiente.

Assim, independentemente de o proprietário desse espaço especialmente protegido ser ente público ou privado, deve respeitar as limitações impostas na sua propriedade, pois essas áreas se sujeitam ao regime jurídico de interesse público.

É importante advertir que a responsabilidade 
ambiental, aplicada ao agente que comete algum tipo de degradação ou impacto ao ambiente, deverá sempre possuir um caráter objetivo. Assim se determinado sujeito praticar algum dano às APAs, deverá ser responsabilizado objetivamente e, dependendo do caso, até criminalmente, com base na Lei n. ${ }^{\circ}$ 9.605/1998 (Lei dos Crimes Ambientais).

É o que se tem evidenciado nos precedentes judiciais do Superior Tribunal de Justiça, como o julgado em 5/8/2004, e publicado no Diário de Justiça no dia 20/9/2004, página 196:

"DANO AMBIENTAL. CORTE DE ÁRVORES NATIVAS EM ÁREA DE PROTEÇÃO AMBIENTAL. RESPONSABILIDADE OBJETIVA.

1. Controvérsia adstrita à legalidade da imposição de multa, por danos causados ao meio ambiente, com respaldo na responsabilidade objetiva, consubstanciada no corte de árvores nativas.

2. A Lei de Política Nacional do Meio Ambiente (Lei 6.938/81) adotou a sistemática da responsabilidade civil objetiva (art. 14, parágrafo $1^{\circ}$ ) e foi integralmente recepcionada pela ordem jurídica atual, de sorte que é irrelevante e impertinente a discussão da conduta do agente (culpa ou dolo) para atribuição do dever de indenizar.

3. A adoção pela lei da responsabilidade civil objetiva significou apreciável avanço no combate à devastação do meio ambiente, uma vez que, sob esse sistema, não se leva em conta, subjetivamente, a conduta do causador do dano, mas a ocorrência do resultado prejudicial ao homem e ao ambiente. Assim sendo, para que se observe a obrigatoriedade da reparação do dano é suficiente, apenas, que se demonstre o nexo causal entre a lesão infligida ao meio ambiente e a ação ou omissão do responsável pelo dano.

4. $\mathrm{O}$ art. $4^{\circ}{ }^{\circ}$, VII, da Lei n. ${ }^{\circ}$ 6.938/81, prevê expressamente o dever do poluidor ou predador de recuperar e/ou indenizar os danos causados, além de possibilitar o reconhecimento da responsabilidade, repise-se, objetiva, do poluidor em indenizar ou reparar os danos causados ao meio ambiente ou aos terceiros afetados por sua atividade, como dito, independentemente da existência de culpa, consoante se infere do art. $14, \S 1 .^{\circ}$, da citada lei.

6. A aplicação de multa, na hipótese de dano ambiental, decorre do poder de polícia mecanismo de frenagem de que dispõe a Administração Pública para conter ou coibir atividades dos particulares que se revelarem nocivas, inconvenientes ao bem-estar social, ao desenvolvimento e à segurança nacional, como sói acontecer na degradação ambiental.

7. Recurso especial provido (REsp 578.797/RS, Rel. Ministro LUIZ FUX, PRIMEIRA TURMA, julgado em 05/08/2004, DJ 20/09/ 2004 p. 196)."

Este julgado serve como paradigma na correta aplicação legislativa interpretada pelo já pacificado entendimento jurisprudencial do Superior Tribunal de Justiça, que considera o ambiente natural como algo de difícil reparação, por ser complexo, logo o indivíduo nunca conseguirá equilibrar o ambiente exatamente como ele se encontrava.

Assim sendo, "basta haver o nexo causal entre a lesão infligida ao meio ambiente e a ação ou omissão do responsável dano", para que seja configurada a Responsabilidade Objetiva do agente, devendo ele reparar o dano causado no ambiente.

A Lei n. ${ }^{\circ}$ 6.902/1981 (sobre a criação de estações ecológicas e áreas de proteção ambiental), em seu Artigo 8. ${ }^{\circ}$, dispõe que:

"Quando houver um relevante interesse público, o Poder Executivo Federal, Estadual e Municipal poderá declarar determinadas áreas dos seus territórios de interesse para a proteção ambiental, a fim de assegurar o bem-estar das 
populações humanas, a proteção, a recuperação e a conservação dos recursos naturais."

Esse aspecto torna as áreas de proteção ambiental uma unidade de conservação em que a capacidade de intervenção do Estado é limitada pelos princípios constitucionais, que estabelecem à coletividade e ao poder público o direito à propriedade. Portanto, dispõe a definição da função social da propriedade rural.

Desse modo, o uso dessas áreas rurais no planejamento de ocupação de determinado território necessitará ocorrer de forma efetiva e conjunta, devendo o município ou o Estado agir conforme os preceitos legais, buscando uma exploração dos recursos naturais das APAs de maneira ecologicamente equilibrada, através da sustentabilidade no ambiente natural.

Para que haja a devida aplicação e interpretação da legislação, deve-se observar a redação do Decreto Federal n. ${ }^{\circ}$ 4.340/2002 (regulamenta artigos da Lei n. ${ }^{\circ} 9.985$, de 18 de julho de 2000, que dispõe sobre o SNUC e dá outras providências), que em seu Art. 17 estabelece que as Áreas de Proteção Ambiental devem dispor de um "Conselho Gestor" composto por representantes dos órgãos públicos e responsáveis por sua administração:

"Art. 17. As categorias de unidade de conservação poderão ter, conforme a Lei n. ${ }^{\circ}$ 9.985, de 2000, conselho consultivo ou deliberativo, que serão presididos pelo chefe da unidade de conservação, o qual designará os demais conselheiros indicados pelos setores a serem representados."

Trata-se, portanto, de um sistema de gestão integrada e participativa, tendo como base para sua sustentação o Plano de Manejo.

Destarte, o Plano de Manejo é definido pela Lei Federal n. ${ }^{\circ}$ 9.985/2000 em seu Art. 27, "caput" e seus parágrafos. Logo, de maneira sucinta, pode- se considerar o Plano de Manejo como sendo "o documento técnico que se baseia nos fundamentos e objetivos gerais de uma Unidade de Conservação, deve estabelecer o seu zoneamento e normas que delimitem o uso das áreas de manejo dos recursos naturais, contendo, ainda, as implementações encontradas nas estruturas físicas necessárias para a gestão da unidade."

Com base no que dispõe a recomendação legal, o Plano de Manejo é consolidado como um documento técnico que traça as diretrizes para se ter um gerenciamento das Áreas de Proteção Ambiental, que posteriormente poderão estabelecer o zoneamento de toda a unidade, de modo a ordenar o uso e a ocupação do solo rural, buscando sempre coibir os impactos ambientais nas Áreas de Proteção Ambiental.

\section{Conclusões}

A APA não atende a sua função social, uma vez que não protege de modo sustentável a utilização do ambiente. Apesar da existência de um extenso plano de manejo, este não está sendo respeitado pelos proprietários rurais, deixando com que ocorram impactos negativos na área.

A agropecuária exercida no local não ocorre dentro dos parâmetros da sustentabilidade, ocasionando inúmeros impactos lesivos ao ambiente.

Pela falta de consciência e educação ambiental da comunidade que reside na APA, e que se utiliza dela como meio de subsistência, verifica-se a ausência de manejo adequado no ambiente e da própria recuperação das áreas degradas.

Outro fator que fica evidente na análise da ausência de funcionamento da APA é a falta de fiscalização por parte do poder público, não sendo exigido, assim, o cumprimento da legislação ambiental vigente.

O que agrava a situação é a falta de interesse do poder público e da coletividade na divulgação da real situação apresentada na APA, transformando este fato em um puro descaso público. 
REFERÊNCIAS

BRASIL, Constituição (1988). Constituição da República Federativa do Brasil. Brasília: Senado, 1988.

BRASIL. Lei n. ${ }^{\circ}$ 4.771/65, de 15 de setembro de 1965. Institui o Novo Código Florestal. http:// www.planalto.gov.br/ccivil_03/Leis/L4771.htm/ acesso 17 out. 2009.

BRASIL. Lei n. ${ }^{\circ}$ 6.902/1981, de 27 de abril de 1981. Dispõe sobre a criação de Estações Ecológicas, Áreas de Proteção Ambiental e dá outras providências. http://www.planalto.gov.br/ ccivil/LEIS/L6902.htm/ acesso em 17 de out. de 2009.

BRASIL. Lei n. 9.605/1998, de 12 de fevereiro de 1998. Dispõe sobre as sanções penais e administrativas derivadas de condutas e atividades lesivas ao meio ambiente, e dá outras providências. http://www.planalto.gov.br/ ccivil_03/Leis/L9605.htm/ acesso 17 out. 2009.

BRASIL. Lei n. 9.985, de 18 de julho de 2000. Regulamenta o Art. $225, \S 1 .^{\circ}$, incisos I, II, III e VII da Constituição Federal de 1988, instituindo o Sistema Nacional de Unidades de Conservação da Natureza e determina outras providências. http://www.planalto.gov.br/ ccivil_03/LEIS/L9985.htm/ acesso 17 out. 2009.

BRASIL. Decreto Federal n. ${ }^{\circ} 4.340$, de 22 de agosto de 2002. Regulamenta artigos da Lei no 9.985, de 18 de julho de 2000, que dispõe sobre o Sistema Nacional de Unidades de Conservação da Natureza - SNUC, e dá outras providências. http://www.planalto.gov.br/ccivil_03/Decreto/ 2002/D4340.htm/ acesso 17 out. 2009.

CAMPO GRANDE. 100 anos de construção.
Campo Grande: Matriz, 1999.

COELHO, L. A importância de Mata Ciliar. $<$ http://www.licenciamentoambiental.eng.br/aimportancia-da-mata-ciliar/ Acesso em 14 ag. 2010.

GUARIROBA. PLANO DE MANEJO DA APA GUARIROBA. http://

www.pmcg.ms.gov.br/SEMADUR/downloads/ 1579PlanodeManejoAPAGuariroba.pdf/ acesso 17 out. 2009.

MILARÉ, É. Direito do Ambiente: Gestão Ambiental em Foco: doutrina, jurisprudência, glossário. $6^{\text {a }}$. ed. São Paulo: Revista dos Tribunais, 2009.

OLIVEIRA, F. M. G. Difusos e Coletivos: Direito Ambiental (Elementos do Direito). São Paulo: Revista dos Tribunais, 2009. v.15.

REBOUÇAS, A. C.; BRAGA, B.; TUNDISI, J. G. Águas doces no Brasil: capital ecológico, uso e conservação. São Paulo: Escrituras, 2006.

RODRIGUES, G. Campo Grande/MS tem potencial hídrico de destaque. http:// www.cienciaenoticia.com.br/?p=791/ acesso 17 out. 2009.

SILVA, J. A. Comentário Contextual à Constituição. São Paulo: Malheiros, 2009.

SILVA, J. A. Direito Ambiental Constitucional. 8. ${ }^{\text {a }}$ ed .São Paulo: Malheiros, 2010.

\section{JULGADOS DO SUPERIOR TRIBUNAL DE JUSTIÇA (STJ) UTILIZADOS COMO REFERÊNCIA:}

REsp 948.921/SP, Rel. Ministro HERMAN BENJAMIN, SEGUNDA TURMA, julgado em 23/10/2007, DJe 11/11/2009. 
REsp 578.797/RS, Rel. Ministro LUIZ FUX, CC 36.666/MG, Rel. Ministro PAULO PRIMEIRA TURMA, julgado em 05/08/2004, DJ GALLOTTI, TERCEIRA SEÇÃO, julgado em 20/09/2004 p. 196.
22/02/2006, DJ 08/02/2008 p. 636. 